Prepared for the U.S. Department of Energy under Contract DE-AC05-76RL01830

Final Report of a CRADA Between Pacific Northwest National Laboratory and the Ford Motor Company (CRADA No. PNNL/265): "Deactivation Mechanisms of Base Metal/Zeolite Urea Selective Catalytic Reduction Materials, and Development of Zeolite-Based Hydrocarbon Adsorber Materials"

F Gao, JH Kwak, JH Lee, D Tran, CHF Peden Pacific Northwest National Laboratory

K Howden Department of Energy

Y Cheng, J Lupescu, G Cavataio, C Lambert, R McCabe Ford Motor Company

February 2012






\title{
DISCLAIMER
}

This report was prepared as an account of work sponsored by an agency of the United States Government. Neither the United States Government nor any agency thereof, nor Battelle Memorial Institute, nor any of their employees, makes any warranty, express or implied, or assumes any legal liability or responsibility for the accuracy, completeness, or usefulness of any information, apparatus, product, or process disclosed, or represents that its use would not infringe privately owned rights. Reference herein to any specific commercial product, process, or service by trade name, trademark, manufacturer, or otherwise does not necessarily constitute or imply its endorsement, recommendation, or favoring by the United States Government or any agency thereof, or Battelle Memorial Institute. The views and opinions of authors expressed herein do not necessarily state or reflect those of the United States Government or any agency thereof.

\author{
PACIFIC NORTHWEST NATIONAL LABORATORY \\ operated by \\ BATTELLE \\ for the \\ UNITED STATES DEPARTMENT OF ENERGY \\ under Contract DE-AC05-76RL01830
}

Printed in the United States of America
Available to DOE and DOE contractors from the Office of Scientific and Technical Information,
P.O. Box 62, Oak Ridge, TN 37831-0062;
ph: (865) 576-8401
fax: $(865)$ 576-5728
email: reports@adonis.osti.gov

\begin{abstract}
Available to the public from the National Technical Information Service, U.S. Department of Commerce, 5285 Port Royal Rd., Springfield, VA 22161 ph: (800) 553-6847 fax: $(703) 605-6900$ email: orders@ntis.fedworld.gov online ordering: http://www.ntis.gov/ordering.htm
\end{abstract}

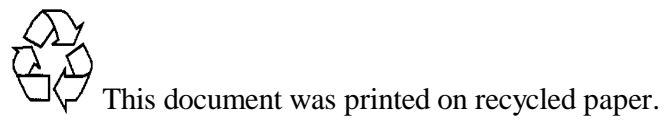




\section{Final Report of a CRADA Between Pacific Northwest National \\ Laboratory and the Ford Motor Company (CRADA No. PNNL/265): \\ "Deactivation Mechanisms of Base Metal/Zeolite Urea Selective \\ Catalytic Reduction Materials, and Development of Zeolite-Based \\ Hydrocarbon Adsorber Materials”}

Feng Gao, Ja Hun Kwak, Jong H. Lee, Diana Tran, Chuck Peden (Primary Contact)

Institute for Integrated Catalysis

Pacific Northwest National Laboratory

P.O. Box 999, MS K8-93

Richland, WA 99354

(509) 371-6501; fax: (509)371-6498; e-mail: chuck.peden@pnnl.gov

DOE Program Manager: Ken Howden

(202) 586-3631; fax: (202)586-7409; e-mail: Ken.Howden@ee.doe.gov

CRADA Partners: Yisun Cheng, Jason Lupescu, Giovanni Cavataio, Christine Lambert, Robert McCabe (Ford Motor Company)

\section{Objectives:}

- Develop an improved understanding of the deactivation mechanisms of the urea selective catalytic reduction (urea SCR) catalyst used in diesel aftertreatment systems.

- Understand similarities and differences between actual field aging and aging under laboratory conditions, information essential in developing a rapid assessment tool for emission control technology development.

- Determine the role of the various aging factors, including poisons like sulfur and phosphorous, and unique aging due to urea exposure that can impact long-term performance of SCR catalyst systems, in order to provide information about what operating conditions or system configurations should be avoided to minimize catalyst deactivation.

- Leverage PNNL's catalyst characterization capabilities and scientific knowledge of zeolite materials to aid Ford in the further development of urea SCR catalysts and systems. 
- Help fuel-efficient advanced combustion engines meet the current and future hydrocarbon (HC) emission standards with effective, inexpensive and reliable $\mathrm{HC}$ adsorber technologies using zeolite materials.

- Improve the understanding of interaction between engine-out HCs and HC adsorber materials during the cold-start and the catalyst warm-up periods.

\section{Accomplishments:}

- Completed studies of the differing effects of $\mathrm{SO}_{2}$ to $\mathrm{SO}_{3}$, including identification of the mechanism of more severe poisoning by $\mathrm{SO}_{3}$, reinforcing that ultralow sulfur fuel is required for high NOx reduction efficiency, and implying that highly loaded Pt oxidation catalysts are not preferred upstream of the SCR catalyst. Pd can be used instead, lowering catalyst system cost. A strategy to desulfate the catalyst at filter regeneration conditions was successful.

- Characterized the nature and distribution of phosphorus deposits observed on engineaged urea SCR catalysts and determined the impact to be less severe than sulfur.

- Performed studies aimed at an understanding of unusual hydrothermal aging of zeolitebased urea SCR catalysts observed at Ford that severely impacted the front edge of the catalyst and changed the nature of the catalyst from reduction to oxidation.

- Investigated the physicochemical properties of model zeolite materials with respect to hydrothermal aging for comparison to commercially available SCR catalyst materials. Identified a $\mathrm{Cu}$ aluminate phase that generated higher NOx conversion at filter regeneration conditions and could result in better SCR catalyst systems with wider temperature windows of operation.

- Evaluated the effects of physicochemical properties of model zeolite materials on the adsorption and desorption of ethanol for E10 to E85 applications.

- Six publications and thirteen public presentations.

\section{Introduction:}

Reducing NOx emissions and particulate matter (PM) are primary concerns for diesel vehicles required to meet current LEV II and future LEV III emission standards which require $90+\%$ NOx conversion. Currently, diesel oxidation catalysts, urea SCR as the NOx reductant [1] and a Catalyzed Diesel Particulate Filter (CDPF) are being used for emission control system components by Ford Motor Company for 2010 and beyond diesel vehicles. Because the use of SCR technology for vehicle applications is new, the relative lack of experience makes it especially challenging to satisfy durability requirements. Of particular concern is being able to realistically simulate actual field aging of the catalyst systems under laboratory conditions. This is necessary both as a rapid assessment tool for verifying improved performance and 
certifiability of new catalyst formulations, and to develop a good understanding of deactivation mechanisms that can be used to develop improved catalyst materials.

In addition to NOx and PM, the hydrocarbon (HC) emission standards are expected to become much more stringent during the next few years. Meanwhile, the engine-out HC emissions are expected to increase and/or be more difficult to remove. Since $\mathrm{HC}$ can be removed only when the catalyst becomes warm enough for its oxidation, three-way catalyst (TWC) and diesel oxidation catalyst (DOC) formulations often contain proprietary zeolite materials to hold the $\mathrm{HC}$ produced during the cold start period until the catalyst reaches its operating temperature (e.g., $>200^{\circ} \mathrm{C}$ ). Unfortunately, much of trapped $\mathrm{HC}$ tends to be released before the catalyst reaches the operating temperature. Among materials effective for trapping HC during the catalyst warm-up period, siliceous zeolites are commonly used because of their high surface area and high stability under typical operating conditions. However, there has been little research on the physical properties of these materials related to the adsorption and release of various hydrocarbon species found in the engine exhaust. For these reasons, automakers and engine manufacturers have difficulty improving their catalytic converters for meeting the stringent $\mathrm{HC}$ emission standards.

In this collaborative program, scientists and engineers in the Institute for Integrated Catalysis at Pacific Northwest National Laboratory and at Ford Motor Company investigated laboratory- and engine-aged SCR catalysts, containing mainly base metal zeolites. These studies led to a better understanding of various aging factors that impact the long-term performance of SCR catalysts and improve the correlation between laboratory and engine aging, saving experimental time and cost. We have also studied materials effective for the temporary storage of $\mathrm{HC}$ species during the cold-start period. In particular, we have examined the adsorption and desorption of various $\mathrm{HC}$ species produced during the combustion with different fuels (e.g., gasoline, E85, diesel) over potential $\mathrm{HC}$ adsorber materials, and measured the kinetic parameters that have potential use in developing system models.

Since this CRADA has now been completed, in this final report we will provide brief summaries of most of the work carried out on this CRADA over the last several years.

\section{Approach:}

This project focused on the characterization of catalyst materials used in the urea SCR and $\mathrm{HC}$ absorber technologies with special attention to changes in the materials properties under conditions of laboratory (e.g., oven and laboratory reactor) and realistic (e.g., engine dynamometer and vehicle) aging protocols. In particular, a primary area of emphasis of earlier studies on this project was establishing the relevance of rapid laboratory catalyst aging protocols with the specific aging phenomena observed in realistic engine operating conditions. This information aided in the development of optimized rapid aging protocols at Ford.

Ford provided both fresh and aged catalyst materials used in the urea SCR technology, and made experimental measurements of changes in the catalytic performance of these materials before and after the aging. PNNL has utilized state-of-the-art analytical techniques to investigate the surface and bulk properties of these catalysts as well as the changes in these properties induced by the aging process. In particular, catalyst characterization techniques such as XRD, XPS, TEM/EDS, BET/pore size distribution, and ${ }^{27} \mathrm{Al}$ solid state NMR have been utilized to probe the changes in physicochemical properties of SCR catalyst and HC absorber samples after 
various pretreatments. This work has been performed on a group of model and development catalysts. Specifically, we have utilized a variety of zeolites, a class of microporous aluminosilicate materials that include a wide range of natural minerals. For SCR, Cu-exchanged beta and SSZ-13 zeolite catalysts were exposed to deactivating conditions; e.g., hydrothermal aging at various temperatures. For HC absorbers, we used candidate catalytic materials that are effective for the temporary storage of HCs produced from different fuels during the cold-start period or advanced combustion processes. Various silicate and aluminosilicate materials, including novel zeolites, were evaluated with respect to hydrophobicity, surface area, pore size and connectivity for the adsorption and desorption of hydrocarbon species found in the engine exhaust. Once the potential materials are characterized, fuel component and combustion product $\mathrm{HC}$ species are used to probe the adsorption and desorption characteristics of different HC adsorber materials. These characterization measurements were complimented by studies at Ford that included performance testing following a variety of laboratory and realistic engine aging protocols.

\section{Results:}

\section{Physicochemical investigations of the degradation mechanisms for SCR catalysts}

NMR Studies of Hydrothermally Aged Cu/Zeolite SCR Catalysts with Urea: The effects of hydrothermal aging of $\mathrm{Cu}$ /zeolite urea-SCR catalysts on their reactivity and material properties was assessed by performance tests and multiple characterization techniques that included ${ }^{27} \mathrm{Al}$ NMR and XRD [2]. Three aging protocols were used that consisted of varying temperature during hydrothermal aging with or without exposure to aqueous urea solution, and the results of NOx performance tests performed after these three different treatments are shown in Figure 1. Differences in behavior were even found for samples hydrothermally aged immediately following exposure to the urea solution or if the sample was dried overnight before hydrothermal aging. The combination of urea and high temperature exposure increased the deactivation of $\mathrm{Cu}$ /zeolite SCR catalysts beyond that observed by hydrothermal aging alone, with an immediate high temperature exposure following wetting of the catalyst core with aqueous urea causing the most significant deterioration in performance. The impact of urea on SCR catalyst durability was also found to increase with the aging temperature. NMR analysis (Figure 2) suggests that aging with urea resulted in relatively more dealumination of the zeolite for the SCR catalysts in this study.

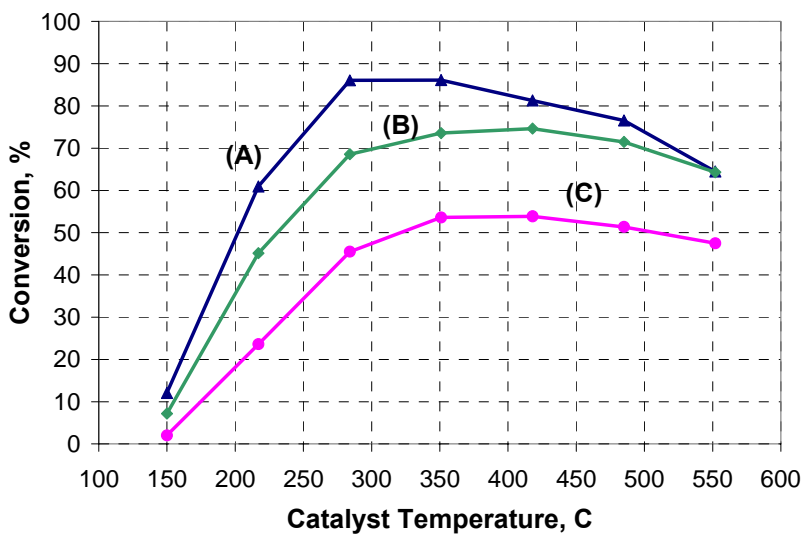

Figure 1: Steady state NOx conversions for a $\mathrm{Cu} /$ zeolite catalyst after aging at $860^{\circ} \mathrm{C}$ for 30 min: (A) hydrothermal aging only; (B) "dry urea" + hydrothermal aging; and (C) "wet urea" + hydrothermal aging. 


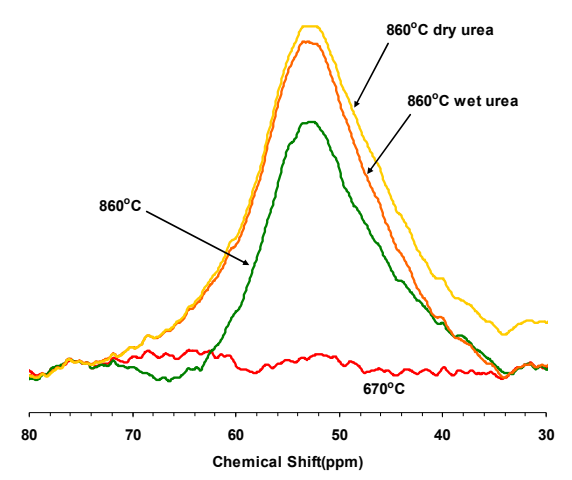

Figure 2: Relative dealumination of a $\mathrm{Cu} /$ zeolite catalyst after aging at $670^{\circ} \mathrm{C}$ hydrothermal only, and after aging at $860^{\circ} \mathrm{C}$ in the three aging conditions.

The Different Impacts of $\mathrm{SO}_{2}$ and $\mathrm{SO}_{3}$ on $\mathrm{Cu} /$ Zeolite SCR Catalysts: The different impacts of $\mathrm{SO}_{2}$ and $\mathrm{SO}_{3}$ on $\mathrm{Cu}$ /zeolite SCR catalysts were investigated by SCR performance tests and multiple characterization techniques including temperature programmed desorption (TPD), X-ray photoelectron spectroscopy (XPS) and X-ray absorption fine structure (XAFS) [3]. The results indicate that a larger amount of highly dispersed $\mathrm{CuSO}_{4}$ formed in the zeolite catalysts $\left(\mathrm{Z}-\mathrm{CuSO}_{4}\right)$ upon $\mathrm{SO}_{3}$ poisoning, explaining the much more significant deactivation of the $\mathrm{Cu} /$ zeolite catalysts that were exposed to $\mathrm{SO}_{3}$ compared to poisoning by $\mathrm{SO}_{2}$. Diesel oxidation catalysts containing high levels of $\mathrm{Pt}$ for $\mathrm{NO}$ oxidation, a common industry strategy to improve low temperature NOx reduction and soot oxidation, also oxidize $\mathrm{SO}_{2}$ to $\mathrm{SO}_{3}$. In these studies, we provided the first demonstration that active sites of $\mathrm{Cu} /$ zeolite SCR catalysts involved in the storage and removal of sulfur can react with $\mathrm{SO}_{2}$ and $\mathrm{SO}_{3}$ in very different ways. In particular, the significant differences in the extent of sulfur uptake account for the considerably different impacts of $\mathrm{SO}_{2}$ and $\mathrm{SO}_{3}$ poisoning on the performance of $\mathrm{Cu}$ /zeolite $\mathrm{SCR}$ catalysts. $\mathrm{The} \mathrm{Cu} /$ zeolite SCR catalyst used in this study was a fully-formulated cordierite monolith with $\mathrm{Cu} /$ zeolite washcoat from a catalyst supplier.

The NOx activities for $\mathrm{Cu} /$ zeolite samples before and after sulfur poisoning by $\mathrm{SO}_{2}$ or $\mathrm{SO}_{3}$ at $200^{\circ} \mathrm{C}, 300^{\circ} \mathrm{C}$, and $400^{\circ} \mathrm{C}$ are shown in Figure 3. Also shown in this figure are results for a freshly degreened catalyst (T1). The NOx activity of $\mathrm{SO}_{2}$-poisoned $\mathrm{Cu}$ /zeolite SCR catalysts decreased to a relatively small extent after being exposed to $40 \mathrm{ppm} \mathrm{SO}_{2}$ for 1.5 hours regardless of the aging temperatures. The lower $\mathrm{SO}_{2}$ aging temperature resulted in higher $\mathrm{NOx}$ activity decreases: the NOx activities performed at $178^{\circ} \mathrm{C}$ decreased by $33 \%$; by $21 \%$ for the sample aged at $300^{\circ} \mathrm{C}$, and only by $8 \%$ for the sample aged at $400^{\circ} \mathrm{C}$. In contrast, the NOx activities of CatA $\mathrm{Cu} /$ zeolite catalysts after sulfur poisoning by $\mathrm{SO}_{3}$ at 200,300 , and $400^{\circ} \mathrm{C}$ were significantly decreased for all samples after being exposed to $40 \mathrm{ppm} \mathrm{SO}_{3}$ for 1.5 hours regardless of the exposure temperatures, with NOx activities of all samples being extremely low at $\mathrm{T}<250^{\circ} \mathrm{C}$. The sample aged with $\mathrm{SO}_{3}$ at lower temperature had better NOx activity between $250^{\circ} \mathrm{C}$ and $340^{\circ} \mathrm{C}$. Notably at a $340^{\circ} \mathrm{C}$ test temperature, the NOx activity of the sample aged at $200^{\circ} \mathrm{C}$ was close to $100 \%$, while the NOx activity of sample aged at $400^{\circ} \mathrm{C}$ showed only $70 \%$ conversion.

In order to obtain the information on the oxidation state and amount of sulfur species, we applied XPS for the $\mathrm{Cu} /$ zeolite catalyst samples treated at $200^{\circ} \mathrm{C}$ with $\mathrm{SO}_{2}$ and $\mathrm{SO}_{3}$. For the 27 $\mathrm{mm}$ (1 inch) long monolith samples, five points were analyzed separated by a distance of $6 \mathrm{~mm}$, allowing us to determine the spatial distribution along the monolith z-axis. Spectra of both samples contain a single peak at $169 \mathrm{eV}$, indicating that only sulfates $\left(\mathrm{SO}_{4}{ }^{2-}\right)$ are formed by the 
interaction with either $\mathrm{SO}_{2}$ or $\mathrm{SO}_{3}$. However, there was a drastic difference in the amount of sulfate species between the samples treated with $\mathrm{SO}_{2}$ or $\mathrm{SO}_{3}$. As shown in Figure 4, the sample treated with $\mathrm{SO}_{3}$ clearly had larger amounts of sulfur, especially up to $13 \mathrm{~mm}$ from the inlet, followed by a significant decrease thereafter. We suggest that sulfate saturates the catalyst from the inlet, gradually moving toward the outlet. In contrast, the sample treated with $\mathrm{SO}_{2}$ had considerably smaller amount of sulfur in the inlet and along the monolith. The summed amounts of sulfur along the monolith indicates that the sample treated with $\mathrm{SO}_{3}$ contained at least five times larger concentrations than the one treated with $\mathrm{SO}_{2}$, which points to the relative ease of sulfate formation by reaction with $\mathrm{SO}_{3}$. XPS results on the samples after the desulfation (deSOx) showed essentially no sulfur remained on the surface of the catalyst (not shown). This result implies that all sulfates are desorbed as a result of thermal desorption during the deSOx, as evidenced also by the full recovery of the activity after deSOx (not shown). The results reinforce that ultralow sulfur diesel fuel is required for modern $\mathrm{Cu}$ /zeolite SCR systems, and Pt upstream of the SCR catalyst is not preferred. Pd is a good alternative for diesel oxidation catalysts that do not oxidize $\mathrm{SO}_{2}$ to $\mathrm{SO}_{3}$.

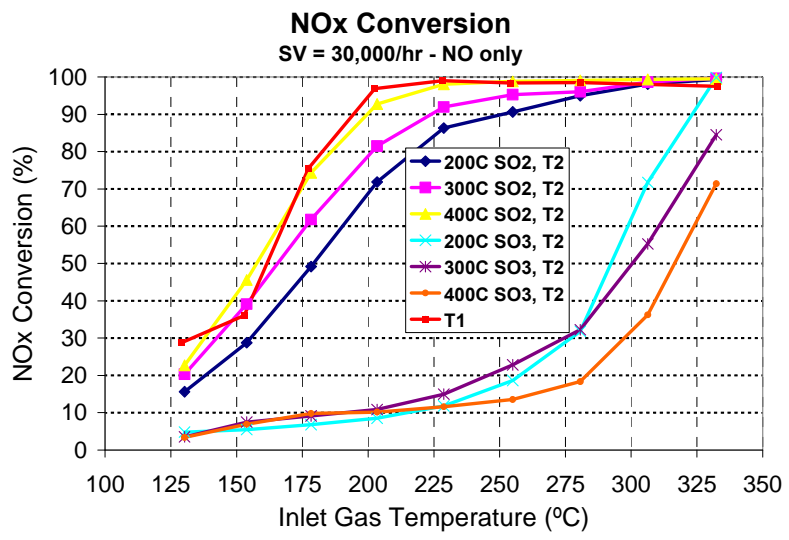

Figure 3: Steady-state NOx conversions for $\mathrm{Cu}$ /zeolite SCR catalysts before and after $\mathrm{SO}_{2}$ and $\mathrm{SO}_{3}$ aging at $200^{\circ} \mathrm{C}, 300^{\circ} \mathrm{C}$, and $400^{\circ} \mathrm{C}$. Also shown are results for a freshly degreened catalyst (T1).

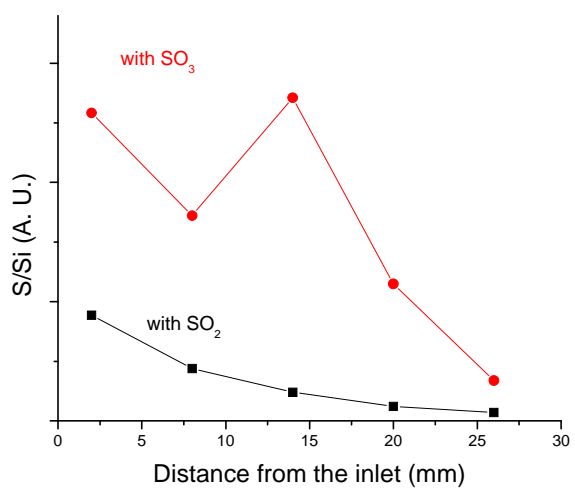

Figure 4: Distribution of sulfur, plotted as normalized S/Si ratios, as a function of distance from the inlet of the monolith-type $\mathrm{Cu} /$ zeolite catalyst.

Non-uniform Aging on Super Duty Diesel Truck Aged Cu/Zeolite Urea SCR Catalysts: Previous studies have shown that deactivation of engine aged SCR catalysts is not uniform, with the inlet section of the catalyst brick deactivating the most and becoming more oxidizing in nature. To better understand this non uniform aging phenomena, a set of $\mathrm{Cu} / \mathrm{zeolite}$ SCR catalysts aged for $50 \mathrm{~K}$ miles on a Super Duty diesel truck were investigated with postmortem analyses emphasizing studies of the inlet section [4,5]. The analyses included catalyst activity evaluation and catalyst characterization, such as BET surface area, TPR, XRF, XPS and TEM. The results suggest that the inlet section of the brick experienced all the aging factors in the most severe way, and that this section deactivates in a more complicated manner than the rest of the brick which mainly deteriorated due to hydrothermal aging. This is demonstrated in Figure 5 which shows a comparison of steady state SCR NOx conversion of cores taken from the middle of the brick, labeled as "M", from the $1^{\text {st }}, 2^{\text {nd }}, 3^{\text {rd }}$, and $5^{\text {th }}$ inch of inlet gas direction. Changes of $\mathrm{Cu}$ state and high levels of $\mathrm{C}, \mathrm{P}$ and $\mathrm{Zn}$ impurities in very front 
region might explain the more severe deactivation of the inlet section of the SCR catalyst. For example, Figure 6 shows the levels of these three impurities as a function of distance from the front of the catalyst monolith obtained by XPS.

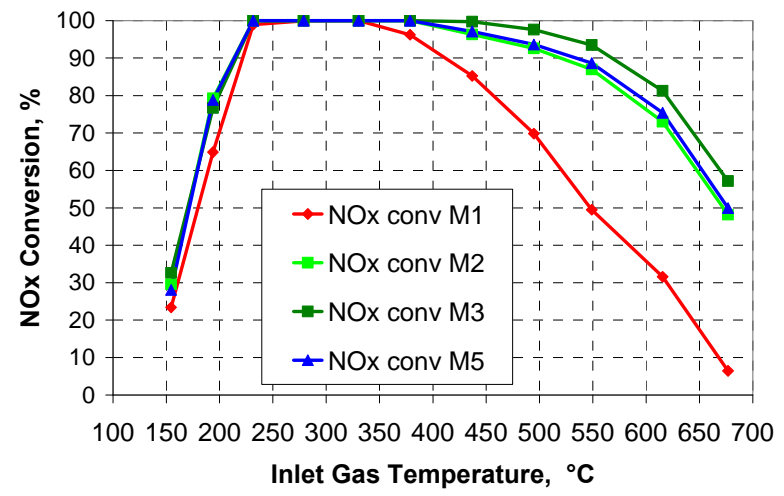

Figure 5: Steady state NOx conversions of engine aged $\mathrm{Cu} / \mathrm{CHA} \mathrm{SCR}$ catalysts.



Figure 6: XPS intensities of carbon (C), phosphorus $(\mathrm{P})$, and zinc $(\mathrm{Zn})$ as a function of distance from the front of a vehicle aged $(50 \mathrm{~K}$ miles) $\mathrm{Cu}$ /zeolite SCR catalyst.

\section{Unusual Performance Behavior for Cu-zeolite SCR catalysts After Mild} Hydrothermal Aging: The hydrothermal stability of $\mathrm{Cu}$ /beta $\mathrm{NH}_{3} \mathrm{SCR}$ catalysts, with respect to their interesting ability to maintain and even enhance high-temperature performance for the "standard" SCR reaction after modest $\left(900^{\circ} \mathrm{C}, 2\right.$ hours) hydrothermal aging, was studied [6]. Characterization of the fresh and aged catalysts was performed with an aim to identify possible catalytic phases responsible for the enhanced high temperature performance. Two model catalysts, suggested by these characterization data as possible mimics of the catalytic phase formed during hydrothermal aging of $\mathrm{Cu} /$ beta, were prepared and tested for their performance in the "standard" SCR and $\mathrm{NH}_{3}$ oxidation reactions. The similarity in their reactivity compared to the 2-hour hydrothermally-aged $\mathrm{Cu}$ /beta catalyst suggests possible routes for preparing multicomponent catalysts that may have wider temperature windows for optimum performance than those provided by current $\mathrm{Cu}$ /zeolite catalysts. As perhaps the most promising zeolite-based SCR catalyst prior to the discovery of the newest generation of CHA zeolite-based materials, the catalyst chosen for this study was $\mathrm{Cu}$ ion-exhanged beta zeolite. The beta zeolite (CP-814C, $\mathrm{Si} / \mathrm{Al}_{2}=38$ ) was obtained from Zeolyst International $\mathrm{Co}$., and $\mathrm{Cu} /$ beta catalysts were prepared by aqueous ion-exchange using a $\mathrm{Cu}\left(\mathrm{NO}_{3}\right)_{2}$ precursor. These $\mathrm{Cu}$-exchanged/beta ( $\mathrm{Cu} /$ beta) catalysts were calcined in an oven at $500^{\circ} \mathrm{C}$ for 2 hours prior to testing and characterization.

As part of studies carried out a couple of years ago at Ford on the comparative hydrothermal stability of several pre-commercial $\mathrm{Cu}$ /zeolite catalysts [7], some very interesting SCR performance behaviour was observed after hydrothermal aging at very high $\left(900^{\circ} \mathrm{C}\right)$ temperatures. In particular, this study described Ford's first observations of an SCR Cu-zeolite formulation (referred to as a "best in class 2007 SCR formulation" in this SAE International paper) that is able to maintain stable NOx performance at $200^{\circ} \mathrm{C}$ after exposure to such severe hydrothermal aging conditions. Not discussed in this paper, however, was the maintenance of unusual high-temperature SCR performance for an older generation catalyst ("best in class 2006 formulation"), even though this latter catalyst's low-temperature activity was reduced significantly due to the high-temperature aging (see Figure 7 in reference [7]). Here, we briefly 
describe our collaborative studies aimed at understanding the properties of zeolite-based catalysts after hydrothermal aging, especially with respect to shedding light on the nature of the material giving rise to this interesting, and potentially useful high temperature SCR performance.
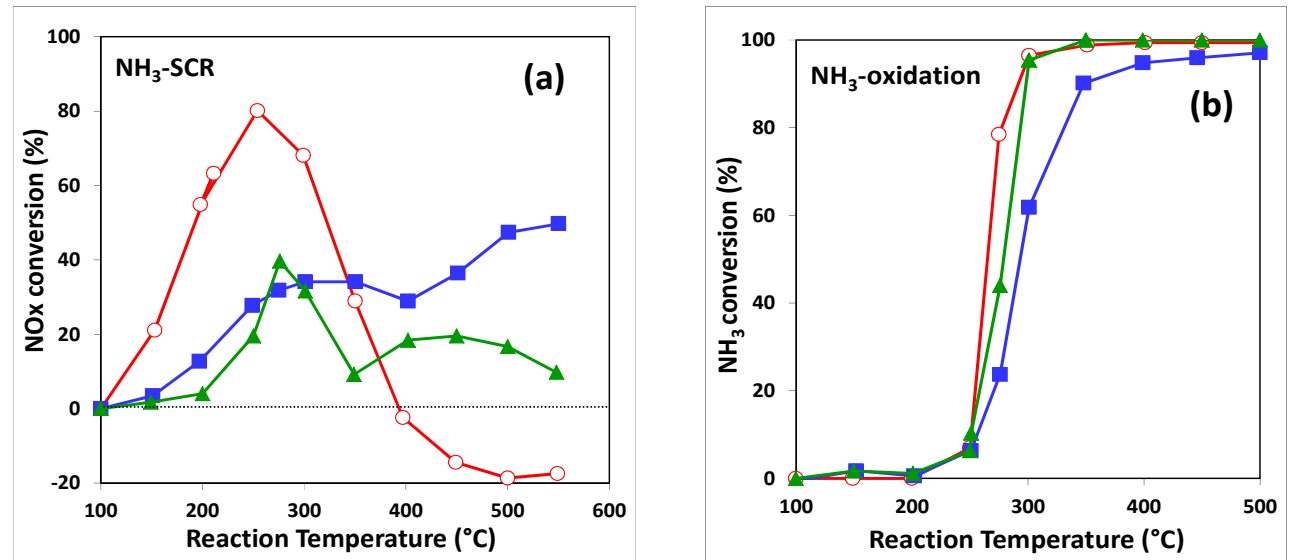

Figure 7: (a) NO conversion to $\mathrm{N}_{2}$ during the "standard" $\mathrm{SCR}$ reaction, and (b) $\mathrm{NH}_{3}$ conversions during the $\mathrm{NH}_{3}$ oxidation reaction (no NOx present) over a Cu-beta zeolite catalyst as a function of temperature after various thermal aging treatments at $900^{\circ} \mathrm{C}: 1$ hour in dry air (open red circles); 2 hours in air with $10 \% \mathrm{H}_{2} \mathrm{O}$ (solid blue squares); and 10 hours in air with $10 \% \mathrm{H}_{2} \mathrm{O}$ (solid dark green triangles). Gas composition for SCR

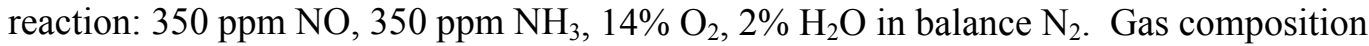
for the $\mathrm{NH}_{3}$ oxidation reaction: $350 \mathrm{ppm} \mathrm{NH}_{3}, 14 \% \mathrm{O}_{2}, 2 \% \mathrm{H}_{2} \mathrm{O}$ in balance $\mathrm{N}_{2}$.

Figure 7 shows results for the temperature dependence of the "standard" SCR (Figure 7a) and $\mathrm{NH}_{3}$ (Figure $7 \mathrm{~b}$ ) oxidation reactions over the $\mathrm{Cu} /$ beta catalyst after various hydrothermal treatments. These treatments, separately performed on fresh catalyst samples, included calcination at $900^{\circ} \mathrm{C}$ for one hour in the absence of $\mathrm{H}_{2} \mathrm{O}$ (red curves), $900^{\circ} \mathrm{C}$ hydrothermal $\left(\mathrm{H}_{2} \mathrm{O}\right.$ present) treatment for 2 hours (blue curves), and hydrothermal treatment at $900^{\circ} \mathrm{C}$ for 10 hours (green curves). Following a $900^{\circ} \mathrm{C}$ calcination without $\mathrm{H}_{2} \mathrm{O}$ present, the $\mathrm{Cu} /$ beta catalyst still displays good performance for the "standard" SCR reaction at lower temperatures (Figure 7a, red curve), although its higher $\left(>300^{\circ} \mathrm{C}\right)$ temperature activity is significantly degraded. In fact, negative NOx conversions observed at temperatures above $400^{\circ} \mathrm{C}$ indicate little, if any, SCR activity for this catalyst aged by calcination, while non-selective $\mathrm{NH}_{3}$ oxidation by $\mathrm{O}_{2}$ (light-off just below $300^{\circ} \mathrm{C}$, red curve in Figure $7 \mathrm{~b}$ ) is responsible for the formation of NOx.

Significantly different "standard" SCR performance data were obtained following a 2hour hydrothermal $\left(\mathrm{H}_{2} \mathrm{O}\right.$ present) aging treatment (Figure 7a, blue curve with square symbols). In this case, while lower $\left(<350^{\circ} \mathrm{C}\right)$ temperature performance is significantly degraded, NOx conversions above $400^{\circ} \mathrm{C}$ are maintained and even perhaps enhanced. Also interesting to note is the fact that the light-off temperature for $\mathrm{NH}_{3}$ oxidation by $\mathrm{O}_{2}$ has increased (Figure $7 \mathrm{~b}$, blue curve). Further increasing the hydrothermal aging time to 10 hours results in a loss of SCR performance for the $\mathrm{Cu}$ /beta catalyst at all temperatures (Figure 7a, green curve). The distinct "standard" SCR and $\mathrm{NH}_{3}$ oxidation activity of the hydrothermally-aged $\mathrm{Cu}$ /beta catalysts, particularly after a relatively short aging time of 2 hours, suggests that a new catalytic phase may have formed during the moderately severe treatment. In order to identify the nature of this potential new phase, we characterized the fresh and aged catalysts with XRD, TEM and ${ }^{27} \mathrm{Al}$ NMR spectroscopy. 
Figure 8 shows the XRD patterns obtained for the fresh (Figure 8a) and hydrothermallyaged $\mathrm{Cu} /$ beta catalysts. In all of these diffraction patterns, only peaks arising from the beta zeolite are evident. Following calcination of the $\mathrm{Cu} /$ beta catalyst at $900{ }^{\circ} \mathrm{C}$ for 1 hour, the diffraction pattern obtained (not shown) is essentially identical to that for the fresh catalyst shown in Figure 8a. After a very short (1 hour) hydrothermal aging treatment, XRD features associated with $\mathrm{Cu} /$ beta are still evident (Figure $8 \mathrm{~b}$ ), although the peaks are somewhat smaller and broader indicating that there has been some loss of the zeolite structure as a result of this treatment. However, increasing the $900{ }^{\circ} \mathrm{C}$ hydrothermal treatment time to 2 hours results in a nearly complete loss of zeolite structure (Figure $8 \mathrm{c}$ ). The small beta zeolite peaks still remaining after 2 hours treatment are essentially fully absent in the diffraction pattern obtained from the sample hydrothermally aged for 10 hours (Figure 8d). For both hydrothermally-aged samples, a broad feature centered at $\sim 22^{\circ} 2 \theta$ indicates the formation of amorphous material.

Strong peaks in the ${ }^{27} \mathrm{Al}$ NMR spectra of alumino-silicate zeolites at $\sim 50-60 \mathrm{ppm}$ (using the signal due to aluminum in an aqueous solution of $\mathrm{Al}\left(\mathrm{NO}_{3}\right)_{3}$ as a $0 \mathrm{ppm}$ reference) are due to tetrahedrally-coordinated $\mathrm{Al}$ atoms that substitutionally occupy Si lattice sites within the zeolite. For fresh $\mathrm{Cu}$-beta zeolite, the peak associated with tetrahedral zeolite-lattice Al appears at $~ 55$ ppm as illustrated in Figure 9 (black curve). Calcination at $900^{\circ} \mathrm{C}$ results in little, if any, change in the ${ }^{27} \mathrm{Al}$ NMR spectrum (Figure 9, red curve), consistent with both XRD and TEM data (not shown). In contrast, hydrothermal aging at $900^{\circ} \mathrm{C}$ for 2 hours results in a dramatic decrease in the size of the peak associated with tetrahedrally-coordinated Al (Figure 9, blue curve). This feature is essentially absent from the $\mathrm{Cu}$ /beta catalyst that was hydrothermally aged for 10 hours (Figure 9, green curve). Note, however, that no new features appear in the spectra for the hydrothermally-aged samples. A possible explanation for this loss of signal in the ${ }^{27} \mathrm{Al} \mathrm{NMR}$ spectra for these aged catalysts is a strong interaction between paramagnetic $\mathrm{Cu}$ and the $\mathrm{Al}$ species that are newly formed as a result of hydrothermal dealumination. Such a strong interaction would render the ${ }^{27} \mathrm{Al}$ NMR signal 'invisible'.

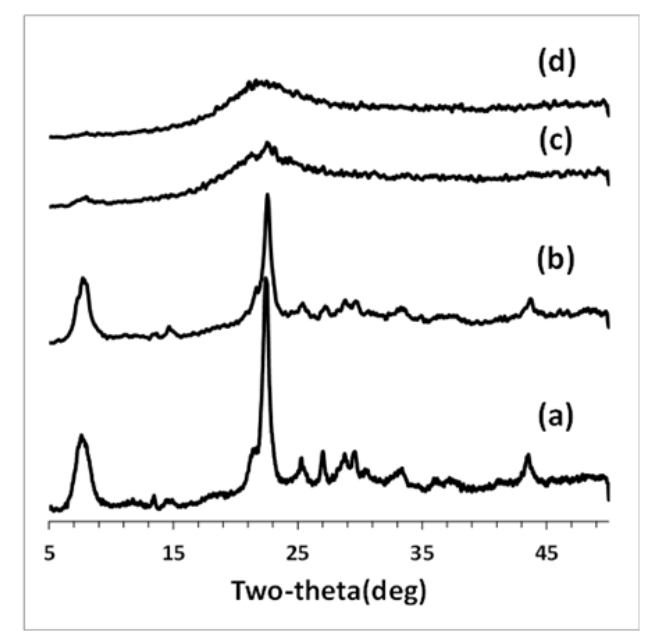

Figure 8: XRD patterns of a fresh $\mathrm{Cu} /$ beta catalyst (a), and after hydrothermal aging at $900^{\circ} \mathrm{C}$ for (b) 1 , (c) 2 , and (d) 10 hours in dry air that contained $2 \% \mathrm{H}_{2} \mathrm{O}$ separately added, at a total gas flow rate during of 500 SCCM.

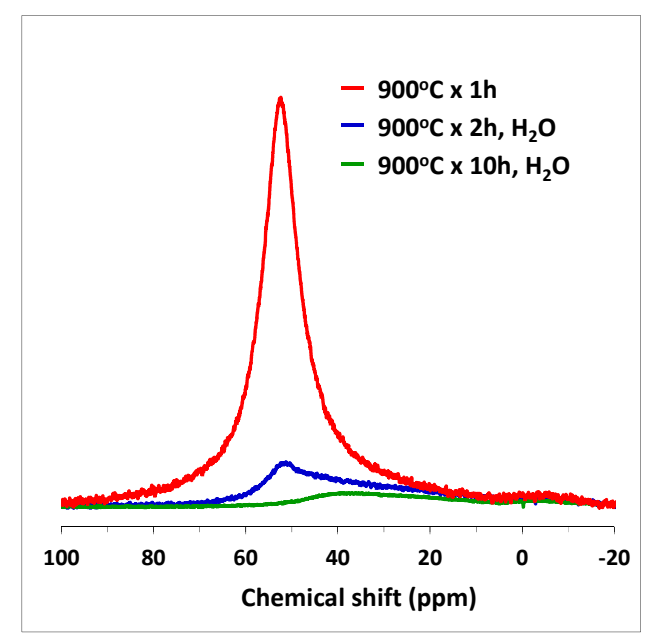

Figure 9: ${ }^{27} \mathrm{Al}$ solid state NMR spectra of the $\mathrm{Cu} /$ beta samples aged at $900^{\circ} \mathrm{C}$ in dry air for 1 hour (red curve), and in dry air that contained $2 \% \mathrm{H}_{2} \mathrm{O}$ separately added for 2 (blue curve) and 10 (green curve) hours. 
The characterization results obtained in these studies were used to suggest possible model catalyst mimics of the catalytic phase formed upon hydrothermal aging that is responsible for its enhanced high temperature performance for the "standard" SCR reaction shown in Figure 7. In fact, the reactivity of the model catalysts (not shown here) were remarkably similar to those of the hydrothermally-aged $\mathrm{Cu} /$ beta catalyst suggesting the possibility that multi-component catalysts can be prepared with wider temperature windows than currently available with $\mathrm{Cu} /$ zeolite catalysts alone. A specific catalyst structure able to achieve both good high- and lowtemperature NOx reduction performance is not proposed here since it will depend on the locations of other emission control components (i.e., diesel oxidation catalyst, diesel particulate filter, etc.). However, the results presented here suggest that an SCR catalyst system consisting of both $\mathrm{Cu}$-zeolite and $\mathrm{Cu}$-alumina materials will provide for a desirably wider temperature window for optimum SCR performance [6].

Deactivation of Cu/Zeolite SCR Catalysts Caused by Phosphorous: A specific role for phosphorus in the loss of SCR performance of $\mathrm{Cu}$ /zeolite was investigated by reactivity tests and catalyst characterization measurements as a function of aging conditions with and without phosphorus [8]. While these studies were not completed during the CRADA, they did demonstrate a possible concern if significant quantities of this species accumulated on the SCR catalyst as a result of the breakdown of engine lubricants. In particular, addition of small amounts of phosphorus species to the gas mixture used during laboratory aging resulted in a small but significant drop in NOx reduction performance at both low and high temperatures for a state-of-the-art $\mathrm{Cu}$ /zeolite catalyst as illustrated in Figure 10. The loss of high temperature activity can be rationalized by enhanced rates of non-selective ammonia oxidation with $\mathrm{P}$ aging as illustrated in Figure 11. To determine possible changes in the $\mathrm{Cu} /$ zeolite catalyst, we characterized these materials after various aging treatments with and without $\mathrm{P}$ with a number of methods.

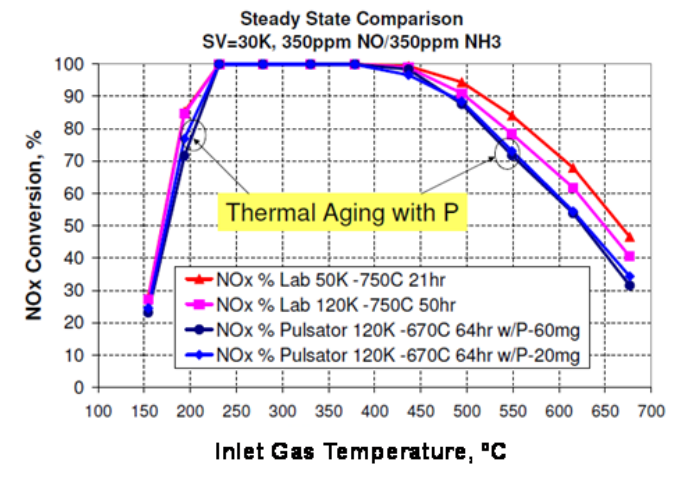

Figure 10: Steady state NOx conversions of lab-aged $\mathrm{Cu} / \mathrm{CHA} \mathrm{SCR}$ catalysts with and without $\mathrm{P}$.

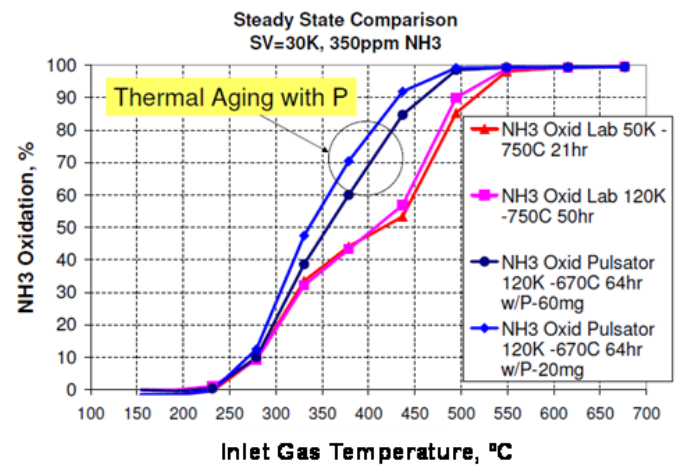

Figure 11: Steady state $\mathrm{NH}_{3}$ oxidation rates of lab-aged $\mathrm{Cu} / \mathrm{CHA}$ SCR catalysts with and without $\mathrm{P}$.

Essentially no differences in surface area were observed for the $\mathrm{Cu}$ /zeolite catalysts as a function of the various lab-aging treatments. Using $\mathrm{NH}_{3} \mathrm{TPD}$ to characterize ammonia storage properties of the variously treated catalysts, a small but consistently observed drop in ammonia adsorption capacity was observed for the catalysts aged in the presence of P. $\mathrm{Cu}(2 \mathrm{p})$ XPS results (not shown) reveal no changes in the state of $\mathrm{Cu}$ even though $\mathrm{P}$ species are readily detected on the P-aged catalysts as shown in Figure 12. ${ }^{31} \mathrm{P}$ NMR studies have tentatively identified two types of phosphorus species that are present as a function of impurity $\mathrm{P}$ levels. This is 
demonstrated in ${ }^{31} \mathrm{P}$ NMR spectra shown Figure 13 for samples that were aged in low (black curve) and high (red curve) P levels. At low levels, the P species appears to be in the form of a monomeric phosphate-like species while the spectrum obtained for the sample with higher $\mathrm{P}$ levels is consistent with the presence of a bulk-like phosphate species. The overall impact was much less severe than sulfur.

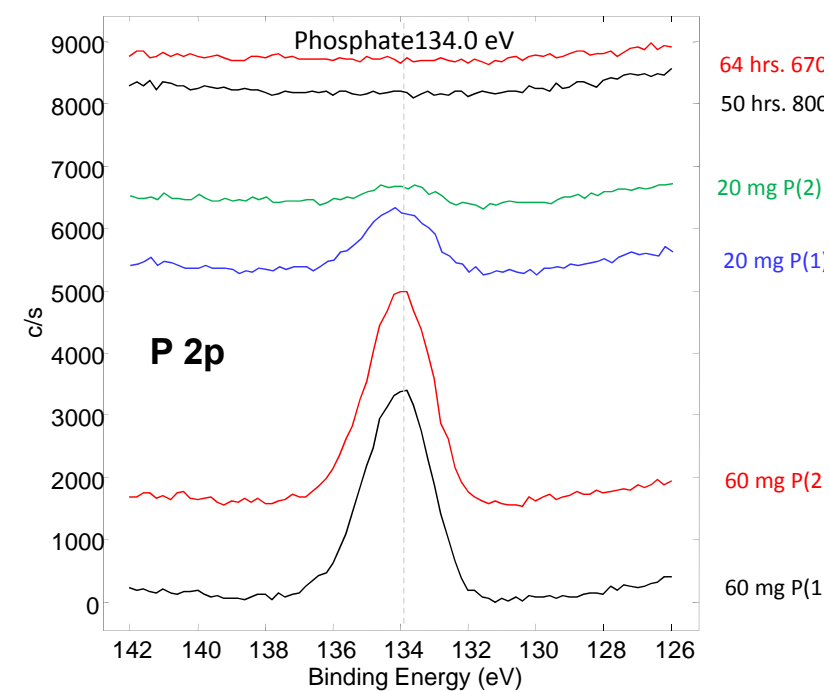

Figure 12: XPS spectra in the $\mathrm{P}(2 \mathrm{P})$ region of a state-of-the-art $\mathrm{Cu}$ /zeolite after laboratory aging with various levels $(0-60 \mathrm{mg})$ of $P$ in the feed. Data was taken at 2 locations ("1" and " 2 ") for the P-aged samples.

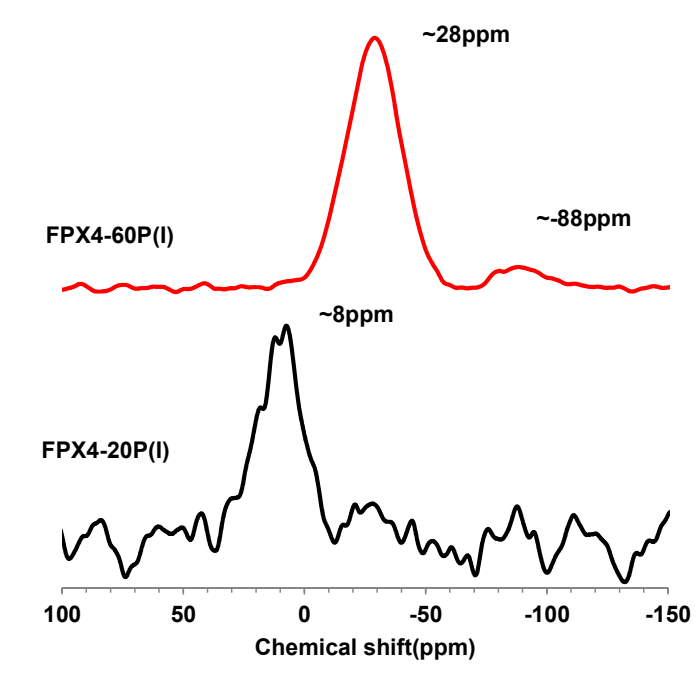

Figure 13: ${ }^{31} \mathrm{P}$ solid state NMR spectra of a state-of-the-art $\mathrm{Cu} /$ zeolite after laboratory aging with various levels of $\mathrm{P}$ in the feed: low (black curve) and high (red curve) P loading.

\section{Physicochemical investigations of $\mathrm{HC}$ absorber materials}

For the last two years of this CRADA, HC adsorbers were investigated with a focus on understanding the effects of various physicochemical properties of zeolite materials [9]. In particular, three model zeolite materials were obtained to probe the effects of different pore size and connectivity: beta (large pore, 3-D pore connectivity); ZSM-5 (medium pore, 3-D pore connectivity); and ZSM-12 (large pore, 1-D pore structure). The effects of hydrothermal aging on their physicochemical properties were then examined using various analytical techniques, including XRD and $\mathrm{NH}_{3}$-TPD. Studies of performance as a function of laboratory aging conditions were carried out at Ford using complex, realistic mixtures of hydrocarbons of various types [10]. For example, Figure 14 shows an example of experiments carried out at Ford that utilize complex hydrocarbon mixtures and a variety of zeolite materials to determine optimized hydrocarbon trap materials for specific applications [9]. In particular, the results shown here were obtained with a hydrocarbon mixture that also contained high concentrations of ethanol and acetaldehyde as expected in the exhausts of E85 fueled vehicles.

At PNNL, detailed catalyst characterization was performed in addition to model studies of performance with gas mixtures containing a single hydrocarbon type. Considering the challenges associated with renewable fuels (e.g., E85), the adsorption and desorption of ethanol was examined in detail. As an example of the mechanistic studies performed, Figure 15 shows temperature-programmed desorption data obtained after exposure of a beta zeolite material to 
ethanol. Both unreacted ethanol $(\mathrm{EtOH})$ and a reaction product, ethylene $\left(\mathrm{C}_{2} \mathrm{H}_{4}\right)$, were observed in the TPD data. Weakly adsorbed ethanol was found to desorb at $<200^{\circ} \mathrm{C}$, whereas chemisorbed ethanol was dehydrated to ethylene which desorbed at higher temperatures (i.e., $>200^{\circ} \mathrm{C}$ ). Interestingly, the presence of water was found to primarily affect the weakly adsorbed ethanol. As also shown in Figure 15, the amount of desorbed ethanol and ethylene from the zeolite depends on the order of water and ethanol exposure, with a post-dose of water leading to the removal of a significant fraction of the adsorbed hydrocarbon species $\left(\mathrm{EtOH}\right.$ and $\left.\mathrm{C}_{2} \mathrm{H}_{4}\right)$ [9].

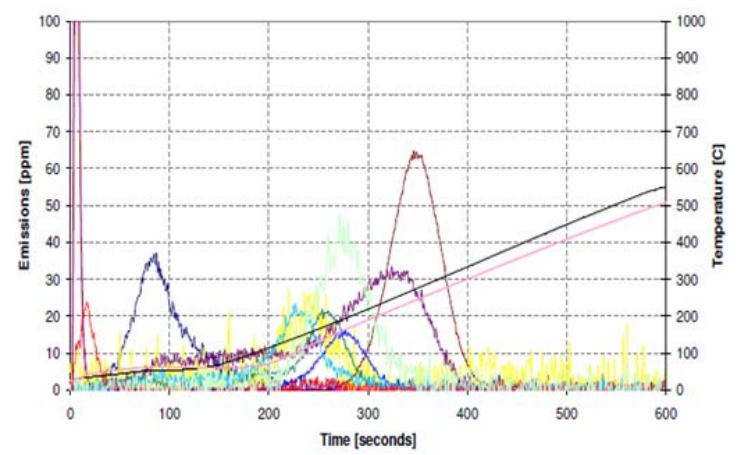

Figure 14: Adsorption/desorption experiment carried out at Ford aimed at determining an optimum zeolite for exhausts of E85 fueled vehicles. A complex hydrocarbon mixture [10], that also included ethanol and acetaldehyde, was used as a realistic model of hydrocarbon exhaust emissions from these vehicles. Among the various desorbing species, ethanol (purple curve) and ethylene (brown curve with peak near 350 seconds) are useful for comparing with model studies.

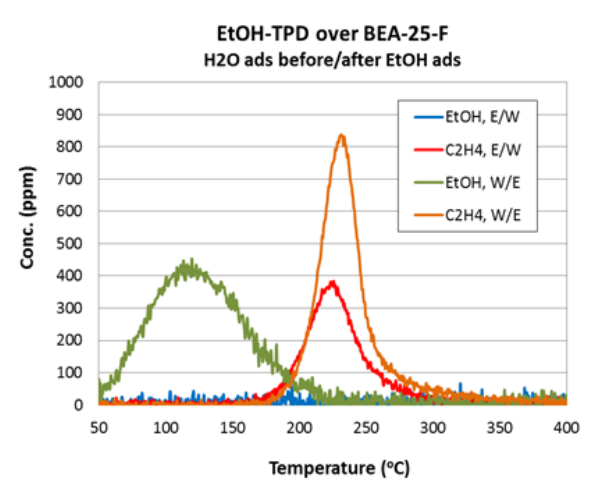

Figure 15: Temperature-programmed desorption (TPD) data obtained after exposure of a beta-zeolite material to ethanol at room temperature. Ethanol exposures were performed before $(E / W)$ and after $(\mathrm{W} / \mathrm{E})$ a separate water exposure to probe the relative stability of these two species.

Following the hydrothermal treatment at $800^{\circ} \mathrm{C}$ for 60 hours, it was found that the surface area, number of acid sites and acidic strength were all reduced significantly, although the zeolite frameworks were found to remain largely intact. Interestingly, the loss of acid sites was more pronounced among samples of high $\mathrm{Si} / \mathrm{Al}$ ratios. Following this hydrothermal treatment, significant loss of ethanol adsorption was observed because of the reduced surface area and acidity.

\section{Conclusions:}

PNNL and its CRADA partners from Ford carried out a program to study the properties and mechanisms of deactivation of SCR and HC-absorber materials arising from thermal aging. Because the catalytically active sites certainly include isolated and very small (even monoatomic) ion-exchanged metals in the zeolite cages, we pursued a molecular-level understanding of the deactivation mechanisms related to the activity degradation by using a number of state-ofthe-art catalyst characterization techniques. This understanding led to improved aging protocols for SCR catalysts and new SCR catalyst system designs. The effects of hydrothermal aging on physicochemical properties of model zeolite hydrocarbon trap materials were also examined. In 
particular, the adsorption and desorption of ethanol on model zeolite materials were investigated with respect to physicochemical properties.

\section{References:}

1. S. Brandenberger, O. Krocher, A. Tissler, R. Althoff, Catal. Rev.-Sci. Eng. 50 (2008) 492-531.

2. Y. Cheng, J. Hoard, C. Lambert, J.H. Kwak, C.H.F. Peden, Catalysis Today 136 (2008) 34-39.

3. Y. Cheng, C.K. Lambert, D.H. Kim, J.H. Kwak, S.J. Cho, C.H.F. Peden, Catalysis Today 151 (2010) 266-270.

4. Y. Cheng, H. Jen, M. Jagner, C.K. Lambert, J.H. Kwak, D.H. Kim, C.H.F. Peden, Oral presentation made by Yisun Cheng at the 2010 DEER Conference (September, 2010).

5. Y. Cheng, M. Jagner, H. Jen, C.K. Lambert, J.H. Kwak, D.H. Kim, C.H.F. Peden, Oral presentation made by Yisun Cheng at the $22^{\text {nd }}$ Meeting of the North American Catalysis Society (June, 2011).

6. C.H.F. Peden, J.H. Kwak, S.D. Burton, R.G. Tonkyn, D.H. Kim, J.H. Lee, H.W. Jen, G. Cavataio, Y. Cheng, C.K. Lambert, Catalysis Today 184 (2012) 245-251.

7. G. Cavataio, H.W. Jen, J.R. Warner, J.W. Girard, J.Y. Kim, C.K. Lambert, SAE 2008-01-1025.

8. Y. Cheng, D. Dobson, C.K. Lambert, J.H. Kwak, C.H.F. Peden, unpublished results.

9. J.H. Kwak, J.H. Lee, C.H.F. Peden, D.N. Tran, Y. Cheng, J. Lupescu, G. Cavataio, C. Lambert, R. McCabe, presentation made by Chuck Peden at the DOE Combustion and Emission Control Review (May, 2012).

10. J.A. Lupescu, T.B. Chanko, J.F. Richert, A.A. Mauti, SAE 2009-01-1068.

\section{Publications (6 total):}

1. F. Gao, J.H. Kwak, J.H. Lee, D.N. Tran, C.H.F. Peden, K. Howden, Y. Cheng, J. Lupescu, G. Cavataio, C. Lambert, R. McCabe, "Deactivation Mechanisms of Base Metal/Zeolite Urea Selective Catalytic Reduction Materials, and Development of ZeoliteBased Hydrocarbon Adsorber Materials", in Advanced Combustion Engine Research and Development: FY2012 Annual Progress Report, in press.

2. C.H.F. Peden, J.H. Kwak, S.D. Burton, R.G. Tonkyn, D.H. Kim, J.H. Lee, H.W. Jen, G. Cavataio, Y. Cheng, and C.K. Lambert, "Possible Origin of Improved High Temperature Performance of Hydrothermally-Aged Cu/Beta Zeolite Catalysts", Catalysis Today 184 (2012) 245-251.

3. J.H. Kwak, J.H. Lee, D.H. Kim, S. Li, D.N. Tran, C.H.F. Peden, K. Howden, Y. Cheng, J. Lupescu, G. Cavataio, C. Lambert, R. McCabe, "Deactivation Mechanisms of Base Metal/Zeolite Urea Selective Catalytic Reduction Materials, and Development of ZeoliteBased Hydrocarbon Adsorber Materials", in Advanced Combustion Engine Research and Development: FY2011 Annual Progress Report, 231-237. 
4. Y. Cheng, C.K. Lambert, D.H. Kim, J.H. Kwak, S.J. Cho, C.H.F. Peden, "The Different Impacts of $\mathrm{SO}_{2}$ and $\mathrm{SO}_{3}$ on $\mathrm{Cu} /$ Zeolite SCR Catalysts." Catalysis Today 151 (2010) 266270.

5. Y. Cheng, C. Montreuil, G. Cavataio, and C. Lambert, "The Effects of $\mathrm{SO}_{2}$ and $\mathrm{SO}_{3}$ Poisoning on Cu/Zeolite SCR Catalysts", SAE 2009-01-0898.

6. Y. Cheng, J. Hoard, C. Lambert, J.H. Kwak, and C.H.F. Peden, "NMR Studies of Cu/zeolite SCR Catalysts Hydrothermally Aged with Urea.” Catalysis Today 136 (2008) 34-39.

\section{Presentations (13 total):}

1. F. Gao, J.H. Kwak, J.H. Lee, C.H.F. Peden, D.N. Tran, Y. Cheng, J. Lupescu, G. Cavataio, C. Lambert, R. McCabe, "Deactivation Mechanisms of Base Metal/Zeolite Urea Selective Catalytic Reduction Materials, and Development of Zeolite-Based Hydrocarbon Adsorber Materials", presentation at the DOE Combustion and Emission Control Review, Washington DC, May, 2013.

2. J.H. Kwak, J.H. Lee, C.H.F. Peden, D.N. Tran, Y. Cheng, J. Lupescu, G. Cavataio, C. Lambert, R. McCabe, "Deactivation Mechanisms of Base Metal/Zeolite Urea Selective Catalytic Reduction Materials, and Development of Zeolite-Based Hydrocarbon Adsorber Materials", presentation at the DOE Combustion and Emission Control Review, Washington DC, May, 2012.

3. Y. Cheng, M. Jagner, H.W. Jen, C.K. Lambert, J.H. Kwak, D.H. Kim, and C.H.F. Peden, "Characterizations of Engine Aged $\mathrm{Cu} / \mathrm{CHA}$ Urea SCR Catalysts", presentation at the 22nd National Meeting of the North American Catalysis Society, Detroit, MI, June 2011.

4. C.H.F. Peden, J.H. Kwak, R.G. Tonkyn, D.H. Kim, J. Szanyi, D.N. Tran, J.H. Lee, "Excellent Activity and Selectivity of Cu-SSZ-13 in the Selective Catalytic Reduction of $\mathrm{NOx}$ with $\mathrm{NH}_{3}$," presentation at the 22nd North American Catalysis Society Meeting, Detroit, MI, June 2011.

5. J.H. Kwak, D.H. Kim, J.H. Lee, C.H.F. Peden, D.N. Tran, Y. Cheng, J. Lupescu, G. Cavataio, C. Lambert, R. McCabe, "Deactivation Mechanisms of Base Metal/Zeolite Urea Selective Catalytic Reduction Materials, and Development of Zeolite-Based Hydrocarbon Adsorber Materials", presentation at the DOE Combustion and Emission Control Review, Washington DC, May, 2011.

6. Y. Cheng, H.W. Jen, M. Jagner, C.K. Lambert, J.H. Kwak, D.H. Kim and C.H.F. Peden, "Non-uniform Aging on Super Duty Diesel Truck Aged Urea Cu/Zeolite SCR Catalysts", presentation at the 2010 DEER Conference, Detroit, MI, September 2010.

7. Y. Cheng, C. Lambert, J.H. Kwak, D.H. Kim, and C.H.F. Peden, "Investigation of Sulfur Deactivation on $\mathrm{Cu} /$ Zeolite SCR Catalysts in Diesel Application", presented at the 2009 Diesel Engine Efficiency and Emissions Reduction (DEER) Conference, Dearborn, MI, August 2009.

8. Y. Cheng, C. Lambert, D.H. Kim, J.H. Kwak, and C.H.F. Peden, "The Different Impacts of $\mathrm{SO}_{2}$ and $\mathrm{SO}_{3}$ on $\mathrm{Cu} /$ Zeolite SCR Catalysts", presentation at the 21 st North American Catalysis Society Meeting, San Francisco, CA. June, 2009.

9. J.H. Kwak, C.H.F. Peden, Y. Cheng, and C. Lambert, "Deactivation Mechanisms of Base Metal/ZeoliteUrea Selective Catalytic Reduction Materials", presentation at the DOE Combustion and Emission Control Review, Washington, DC, May 2009. 
10. Y. Cheng, C. Montreuil, G. Cavataio, C. Lambert, and D. Dobson, "Investigation of the Sensitivity of Base Metal/Zeolite SCR to $\mathrm{SO}_{3}$ Deactivation", presentation at the SAE Light-Duty Diesel Emission Control Symposium, Ypsilanti, MI, November, 2008.

11. Y. Cheng, C. Lambert, J.H. Kwak, and C.H.F. Peden, "Understanding the Deactivation Mechanisms of Cu/Zeolite SCR Catalysts in Diesel Applications", presented at the 2008 Diesel Engine Efficiency and Emissions Reduction (DEER) Conference, Dearborn, MI, August 2008.

12. J.H. Kwak, C.H.F. Peden, Y. Cheng, H. Hoard, and C. Lambert, "Deactivation Mechanisms of Base Metal/ZeoliteUrea Selective Catalytic Reduction Materials", presentation at the DOE Combustion and Emission Control Review, Washington, DC, February 2008.

13. Y. Cheng, J. Hoard, C. Lambert, J.H. Kwak, and C.H.F. Peden. 2007, "The Impact of Urea on Hydrothermally Aged Cu/Zeolite SCR Catalysts, "presented at the 20th North American Meeting of the Catalysis Society, Houston, TX, June 2007.

\section{Acronyms:}

ACS: American Chemical Society

BET: Branauer-Emmet-Teller particle surface area and pore-size measurement method CARB: California Air Resources Board

CDPF: catalyzed diesel particulate filter

CRADA: cooperative research and development agreement

DOC: diesel oxidation catalyst

DPF: diesel particulate filter

E85: gasoline fuel blend containing $85 \%$ ethanol

EDX: energy dispersive $\mathrm{x}$-ray spectroscopy

EPA: Environmental Protection Agency

HC: hydrocarbons

HCCI: homogeneous charge compression ignition

LEV: low emission vehicle

NMR: nuclear magnetic resonance

NOx: nitrogen oxides ( $\mathrm{NO}$ and $\mathrm{NO}_{2}$ )

ORNL: Oak Ridge National Laboratory

PCCI: premixed charge compression ignition

PGM: platinum group metal

PNNL: Pacific Northwest National Laboratory

SAE: Society of Automotive Engineers

SCR: selective catalytic reduction

SEM: scanning electron microscopy

STEM: scanning transmission electron microscopy

SULEV: super ultralow emission vehicle

TEM: transmission electron microscopy

TPD/TPRX: temperature programmed desorption/temperature programmed reaction

TWC: three-way catalyst

XPS: x-ray photoelectron spectroscopy

XRD: $x$-ray diffraction 